\title{
Mechanisms and dynamics of bubble coalescence in silicic magmas
}

Jonathan M. Castro (University of Mainz)

Alain Burgisser (ISTO-CNRS)

Ian Schipper (ISTO-CNRS)

Simona Mancini (ISTO-Université d'Orléans)

\section{Abstract}

Bubble coalescence is an important process that strongly affects magmatic degassing. Without coalescence, bubbles remain isolated from one another in the melt, severely limiting gas release. Despite this fact, very little has been done to identify coalescence mechanisms in textures of magmatic rocks, or to quantify the dynamics of bubble coalescence in melts. In this paper, we present a systematic study of bubble-coalescence mechanisms and dynamics in natural and experimentally produced bubbly rhyolite magma. We have used a combination of natural observations aided by high-resolution X-Ray computed tomography, petrological experiments, and physical models to identify different types of bubble-bubble interaction that lead to coalescence on the timescales of magma ascent and eruption. Our observations and calculations suggest that bubbles most efficiently coalesce when inter-bubble melt walls thin by stretching rather than by the commonly invoked mechanism of melt drainage from between converging bubble walls. Orders of magnitude more rapid than melt drainage, bubble wall stretching produces walls thin enough such that inter-bubble pressure gradients may cause the melt wall to dimple the melt wall, further enhancing coalescence. To put these results into volcanogical context, we have identified magma ascent conditions where each coalescence mechanism should act, and discuss the physical conditions for preserving coalescence structures in natural pumice. The timescales we propose have the potential to improve volcanic eruption models, which currently do not account for bubble coalescence. Although we do not address the effect of shear strain on bubble 
coalescence, the processes discussed here may operate in several different eruption regimes, including vesiculation of lava domes, post-fragmentation frothing of vulcanian bombs, and bubbling of pyroclasts in conduits.

\section{Introduction}

Volcanic eruptions are initiated, sustained, and then halted by the action of pressurized vapour that ascends along with liquid (and/or crystalline) magma. It is the effectiveness of physical separation of gas from its parent magma, or "degassing", that dictates the vigour and course of the eruption. Efficient magma degassing involves the decompression-induced nucleation and growth of bubbles, connection or coalescence of these bubbles with oneanother, and finally the percolation of gas through the channels formed by coalescence. In concert, these processes may influence whether or not the magma explosively fragments or flows as lava (e.g., Eichelberger, 1995), by controlling the permeability (Eichelberger et al., 1986; Blower et al., 2001a) and therefore, the amount and rate of outgassing (e.g., Gonnermann and Manga, 2007). Understanding bubble coalescence is therefore critical, given its role in controlling permeability, the separation of gas from magma, and hence eruption dynamics. Volcanic eruption models aimed at simulating the ascent of viscous magmas (e.g., Woods and Koyaguchi, 1994; Melnik and Sparks, 1999; Yoshida and Koyaguchi, 1999; Slezin, 2003; Kozono and Koyaguchi, 2009) currently lack any formulation describing how coalescence relates to the growth of two or more bubbles. As a result, bubbles in these models grow only by gas expansion and water diffusion from melt to gas, which leaves out not only a potent growth mechanism, but also the major control of permeability.

Observations of natural and experimental bubbly volcanic materials suggest that bubbles can coalesce at porosities well below those in magmatic foam (ie., at porosities 
$<<75 \%$, the packing limit for equal sized spherical bubbles; e.g., Klug and Cashman, 1996; Westrich and Eichelberger, 1994), and the process may be enhanced by shear strain (Burgisser and Gardner, 2005; Okumura et al., 2006). In principle, coalescence will occur when two or more bubbles grow close enough together and to large enough sizes that they begin to do mechanical work on the melt between them. In the published literature, this mechanical work has been analyzed exclusively in the framework of liquid-film drainage in static foams (Proussevitch et al., 1993). In this context, bubble-melt walls are inherently unstable due to the capillary forces that attempt to re-round the flattened inter-bubble walls. The resulting pressure gradient drives fluid flow away from the center of the melt film towards the plateau borders at the margins of the bubbles. When the wall thickness reaches a critical minimum value, films then rupture due to instabilities arising from van der Waals forces (e.g., Vaynblat et al, 2001) and the melt films retract if there is enough time to do so before quenching.

As suggested by Navon and Lyakhovsky (1998), the equations describing bubble coalescence in foams are not applicable to lower porosity systems because bubble expansion may cause stretching rather than drainage of inter-bubble melt films (IBF); the primary difference between these two mechanisms lies in the nature of the vapour-melt boundary, which moves during stretching as opposed to being stationary during drainage (Toramaru, 1988). This boundary layer distinction becomes especially important in the case of highsilica magma because, as we demonstrate below, the timescales for film drainage are much longer than for stretching. As a result, melt-wall stretching offers a far more efficient mechanism for bubbles to coalesce on eruptive timescales. When the IBFs are thin compared to the bubble radii, a difference in the internal vapor pressures between adjacent bubbles may be sufficient to deform the IBF. Such deformations will be present in vesicular eruption 
products (Fig. 1; Klug and Cashman, 1996) if the system quenches shortly after the bubble walls deform.

Here we examine the mechanisms and timescales of bubble coalescence in natural and experimental low-porosity $(<40 \%)$ rhyolite, focusing particularly on the IBF forms that presage the connection of two or more bubbles. We have used X-Ray computed microtomography $(\mu-C T)$ to identify the 3D morphologies of IBFs characteristic of different deposit types and experimental decompression regimes (Burgisser and Gardner, 2005), which in turn, provides insights into the mechanical interactions between growing bubbles.

\section{Samples and methods}

Natural observations were made on low- to intermediate-porosity $(10 \sim 40 \%)$ rhyolitic pumice and obsidian samples from Krafla and Chaitén volcanoes (Table 1). The samples come from, respectively, 1) an incipiently vesiculated, 10-cm diameter obsidian clast sampled from a rhyolite feeder dike at Hraffntinyguur (Tuffen and Castro, 2009), near Krafla volcano, Iceland, and 2) several small ( $\sim 3 \mathrm{~mm})$ poorly vesicular pumice lapilli from a Plinian air-fall deposit formed in the May, 2008 eruption of Chaitén volcano, Chile. Crystallinity in both sample types occurs mainly in the form of phenocrysts and scarce microlites amounting for $<2$ vol. $\%$ of the bulk samples. The $\mathrm{H}_{2} \mathrm{O}$ contents of the Krafla and Chaiten rhyolites range from about $0.5 \mathrm{wt} \%$ in the Hraffntinyguur dike to about $0.6-1.0 \mathrm{wt} . \%$ in the Plinian lapilli, as determined by synchrotron-FTIR (Tuffen and Castro, 2009; Castro and Dingwell, 2009).

We also examined experimental bubble textures produced in rhyolite melt at $825^{\circ} \mathrm{C}$, variable decompression rates (0.025-10 $\left.\mathrm{MPa} \mathrm{sec}^{-1}\right)$ and quench pressures (30-50 MPa; Burgisser and Gardner, 2005). These conditions simulate a range of magma ascent velocities $\left(1-100 \mathrm{~cm} \mathrm{sec}^{-1}\right)$ and quench depths $<1 \mathrm{~km}$. The experimental conditions and starting material closely replicate the inferred magma storage and eruption conditions of the Chaitén rhyolite 
(Castro and Dingwell, 2009), and thus, constitute an excellent framework with which to compare the natural rhyolitic samples. The experimental protocol involved linear decompression of water-saturated melt from a starting pressure of $100 \mathrm{MPa}$, followed by rapid quenching in a water-cooled device. The estimated time for the decompressed melts to cool below the glass transition temperature is estimated to be $\sim 3$ seconds $\left(70{ }^{\circ} \mathrm{C} \mathrm{sec}^{-1}\right)$. Further experimental details are provided in Burgisser and Gardner (2005).

Among the decompression experiments, we focused solely on those quenched at or around $40 \mathrm{MPa}$, which allowed side-by-side comparison of experiments conducted at different decompression rates, and hence, evaluation of the effect of decompression timescale on coalescence behavior (Table 1). The relatively high quench pressure also created generally lower melt porosities and spherical bubble morphologies, which eliminated the effect of deformation due to crowding as the bubbles expanded against the capsule walls. These conditions also produced samples with a large number of bubble pairs, which could be analyzed as a case for two bubbles interacting without competing influences of a third or fourth neighboring bubble.

The X-Ray $\mu$-CT analyses were performed with a Phoenix Nanotom 180, using a molybdenum target, tungsten filament, variable operating voltage (100-180 KeV) and filament current (50-210 $\mathrm{nA})$. We analyzed small (1-4 $\left.\mathrm{mm}^{3}\right)$ chips of vesicular glass by mounting them to carbon fiber rods with thermoplastic adhesive. The samples were then rotated through $360^{\circ}$ during the exposure to the X-radiation. Between 1300 and 2300 images were collected during each analysis. Reconstruction of these images into a stack of greyscale images representing different phases was performed with a separate PC microcluster running Phoenix reconstruction software. The voxel edge-length for most scans was 1-4 $\mu \mathrm{m}$. This resolution was sufficient for detecting the geometry of melt films between most bubbles, 
however, many melt films were thinner than the scan resolution, resulting in loss of information at film thicknesses of $<1 \mu \mathrm{m}$.

Following reconstructions, we selected 3-5 sub-regions of each 3D stack for further detailed textural analysis. The 3D characteristics of the experimental charges, including the de-coalesced bubble size distribution, inter-bubble wall shapes, and wall thicknesses were measured on the binary image stacks with Blob3D software (Ketcham, 2005). We measured the wavelengths, amplitudes, and thicknesses of the IBFs at the point of their maximum deflection between the bubbles. More details are given in the Appendix.

\section{Natural and experimental bubble structures}

Figure1 shows a collection of tomographic renderings of natural vesicle populations in low-porosity obsidian lapilli (a-d) including individual extracted pairs (e-h) that highlight IBF morphologies. IBF shapes in these samples range from perfectly flat to bi-concave shaped with occasional forms having a dimpled appearance. Flat-walled IBFs are by far the most dominant type, with bi-concave IBFs being relatively common in the lowest porosity domains. Figure 2 shows two examples of rhyolite pumice vesicle populations. In each, the bubble diameters and number densities are much larger than can be clearly shown in a $2 \mathrm{D}$ tomographic rendering. To fix this problem we truncated the stacks to show just a few representative bubble walls. In the natural pumice, the most common IBF form is a highly thinned $(<1 \mu \mathrm{m}-5 \mu \mathrm{m})$ flat wall. Few vesicles in these samples are spherical; most seem to have stretched along with bulk sample deformation or due to local impinging of larger bubbles on one another.

Figures 3 and 4 show $\mu$-CT scans of textures in bubble populations and representative vesicle size distributions of rhyolite decompression experiments, respectively (Burgisser and Gardner, 2005). The forms of the IBFs vary with decompression time, reflecting to a first 
order the effect of increasing porosity and concomitant crowding of bubbles on one-another (Table 1). The highest decompression rate experiments (10 and $\left.1 \mathrm{MPa} \mathrm{sec}^{-1}\right)$ contain IBFs characterized by planar or slightly curved forms (Fig. 3b, d), whereas the slower runs produce IBFs with either flat walls or dome-into-dimple shapes (Fig. 3c, e). Below quench pressures of $40 \mathrm{MPa}$, IBFs in slow decompression runs are predominantly contorted (Fig. 3f), and some contain vestiges of dimple structures.

Within bubble populations having abundant dimpled IBFs, there is no systematic relationship between relative bubble sizes and the directionality of the dimple. That is, either the larger or the smaller bubble may penetrate the neighboring bubble (Fig. 5). We notice also that bubbles that may be multiply dimpled, where one bubble shares two of its walls with neighboring bubbles (Fig. 3c). It is common to find directionality when multiple dimples are present, that is, a bubble will have a penetrative dimple from one bubble whilst penetrating the next. The dimple structures always occur where the distance between two or more neighboring bubbles is at a minimum. From our observations, the maximum IBF thickness corresponding to the onset of deformation into a dimple is about $8 \mu \mathrm{m}$.

\section{Quantifying IBF-thinning timescales and coalescence dynamics}

In comparing experimental bubble-bubble textures to the natural ones, we see that both types of sample contain an abundance of planar IBFs and much fewer bi-concave IBFs. Experiments produce interesting dome-into-dimple structures, whereas the natural materials contain few, and poorly preserved structures (Fig. 1d, h). In order to understand the formation of these IBF structures and how they may aid coalescence, we must first constrain the feasible mechanisms and timescales over which melt between converging bubbles thins.

\subsection{Thinning by drainage}


The widely held view is that two bubbles coalesce when liquid drains away from the center of the IBF towards plateau borders through a fixed geometry in which the bubble-melt interfaces are immobile (e.g., Proussevitch et al., 1993). Neglecting gravity forces, a diskshaped melt film of radius $a_{0}$ drains from an initial thickness $z_{0}$ to a critical thickness $z_{f}$ after a time $\left(t_{\text {drain }}\right)$ given by (Toramaru, 1988; Proussevitch et al., 1993):

$$
t_{\text {drain }}=\left(\frac{1}{z_{f}}-\frac{1}{z_{0}}\right) \frac{3 a_{0}^{2} \mu}{\sigma\left(\frac{1}{R_{1}}+\frac{1}{R_{2}}\right)}
$$

where $\sigma$ is surface tension and $\mu$ is the melt viscosity (Table 2). The critical thickness $z_{f}$ is the minimum-melt film thickness below which liquid instabilities cause rupture. Our tomographic scans show that IBFs are broken or discontinuous when thicknesses are about $0.5 \mu \mathrm{m}$ or less, thus $z_{f}=0.5 \mu \mathrm{m}$ is appropriate. Here, the driving force for drainage is the capillary stress arising from surface tension, which acts to maintain bubble sphericity. According to equation 1, an IBF in basaltic melt having a viscosity of $O(2) \mathrm{Pa}$ sec would thin to the critical thickness $(\sim 0.5 \mu \mathrm{m})$ in about 100 seconds, whilst in rhyolitic melt $\left(\mu \sim 10^{6}-10^{9}\right.$ Pa sec), $t_{\text {drain }}$ ranges from $10^{4}$ to $10^{7}$ sec (e.g., Navon and Lyakhovsky, 1998). Considering these timescales, IBF thinning by melt drainage is probably not important in natural (e.g., Klug and Cashman, 1996) or experimental rhyolite (Burgisser and Gardner, 2005), but should operate on eruptive timescales in mafic melts.

\subsection{Thinning by stretching}

IBF thinning and rupture in high-silica magma requires a faster mechanism than drainage. IBF thinning is quicker if it is physically coupled to bubble growth; in this case the melt film is stretched rather than drained through a fixed geometry. As growing bubbles displace surrounding melt, the IBF should thin to accommodate this displacement because, in 
the limit that the bubble-growth time is much shorter than the draining timescale $\left(t_{\text {drain }}\right)$, mass will be conserved within the IBF and the melt film will extend as the bubbles grow (e.g., Navon and Lyakhovsky, 1998).

We can obtain a first-order estimate of the decay of the IBF during bubble growth by considering a simplified arrangement of two hemispherical bubbles bounding two discs of radius $a(t)$ (Fig. 6). As the bubbles grow radially, the IBF, delineated by the positions of the two discs must also extend incrementally in the radial direction. In order for the mass trapped within the IBF to be conserved during this stretching, it must shorten or thin along the perpendicular direction. To a first order, the discs follow the bubble growth rate, $\dot{R}$ (i.e. $a(t)=a_{0}+\dot{R} t$, where $a_{0}$ is the initial disc radius, Fig. 6b). Mass conservation imposes that $\pi a_{0}^{2} z_{0}=\pi a^{2}(t) z(t)$, and the time to reach the critical thickness, $z_{f}$, is given by:

$$
t_{\text {planar }}=\frac{a_{0}}{\dot{R}}\left(\sqrt{\frac{z_{0}}{z_{f}}}-1\right)
$$

Considering permissible growth rates in the experiments we see that growth-induced thinning may take place over timescales ranging from seconds to hours (Fig. 7).

\subsection{Thinning by dimpling}

The dimpled IBFs observed in the rhyolite experiments comprise symmetrical dome structures whose apex occurs where the distance between two or more neighboring bubbles is a minimum (Fig. 3e). Experimentally quenched samples display dimpled IBFs at various stages of formation. Our observations suggest that when deformation starts, the IBFs have two concave surfaces because bubbles are sub-spherical. Deformation then proceeds to bend the IBF, thinning its apex until it finally ruptures and the two bubbles coalesce. Addressing IBF bending in detail is challenging because the process involves the two growing bubbles and the surrounding melt. We simplify the geometry by considering only the motion of the 
IBF itself, which is represented as a thin cylindrical film fixed at its perimeter and subjected to a perpendicular forcing (Fig. 6c). The evolution of the film shape is controlled by strongly nonlinear, time-dependent equations that require numerical solutions (Ida and Miksis, 1995; Howell, 1996) and at least two images of dimpling at different times to compare with experimental data. Those data, however, comprise only one snapshot of dimpling, which is insufficient to carry out a detailed comparison. We thus use a first-order approach to quantify the controls of dimpling. Neglecting van der Waals forces because IBFs are typically $>1 \mu \mathrm{m}$ thick, there are three physical quantities involved in the process: surface tension, viscous resistance of the IBF, and driving force.

In the absence of external forcing, surface tension will tend to erase dimples. This relaxation of the dimpled bubbles into spheres will occur over a timescale, $t_{\text {relax }}$, given by Rust et al. (2003):

$t_{\text {relax }}=\frac{R \mu}{\sigma}$

Here, $R$ is the equivalent bubble radius (i.e. the radius of an undeformed sphere of equal volume). Dimpling requires that external forcing occurs and overcomes surface tension. Although insufficient to prevent dimpling, surface tension will effectively "use up" a fraction of the applied driving force. If the driving force were distributed evenly across both IBF surfaces, surface tension would tend to force them into spherical shapes.

Neglecting surface tension, Ribe (2001) proposed first-order estimates of thin film deformation that include driving force and the viscous resistance of the film. Results from Ribe's (2001) study include the response of an initially flat cylindrical film fixed at its extremities and subjected to a pressure drop across its thickness. This arrangement corresponds to our simplification of a dimpling IBF. The film deforms itself first by elastic stretching without changing its thickness and then by bending while thinning. Stretching occurs over a timescale $t_{\text {stretch }}$ given by (Ribe, 2001): 
$t_{\text {stretch }}=\frac{z_{0} \mu}{2 a_{0} \Delta P}$

and bending occurs over a timescale $t_{\text {bend }}$ given by:

$$
t_{\text {bend }}=\frac{\mu}{\Delta P}\left(\frac{z_{0}}{2 a_{0}}\right)^{4}
$$

where $a_{0}$ is the radius of the IBF when it is flat (which corresponds to the half-wavelength of the deformed IBF, Fig. 6c), and $z_{0}$ is the IBF initial thickness. In the limit of very thick IBFs $\left(z_{0}>>a_{0}\right)$, the deformation approaches that of a plane Poiseuille flow, which shapes the surfaces into paraboloids (Tuck et al., 1997).

The driving force behind IBF dimpling could be gradients in surface tension along the IBF surfaces, which could cause deformation by Marangoni effect. Surface tension can vary with temperature (Gardner and Ketcham, 2011) and water content (Mangan and Sisson, 2005). This is not expected because experiments were isothermal and dimples occur at various decompression rates, including slow rates that ensure equilibrium degassing and no dissolved water gradients. In the absence of large scale stresses such as shearing along the capsule walls and when bubbles are initially spherical, the stress available to deform the bubble wall is the vapor pressure difference between the two bubbles $(\Delta \mathrm{P})$, which includes contributions from surface tension and viscous resistance to growth (e.g., Blower et al., 2001b):

$$
\Delta P=2 \sigma\left(\frac{1}{R_{1}}-\frac{1}{R_{2}}\right)+4 \mu\left(\frac{\dot{R}_{1}}{R_{1}}-\frac{\dot{R}_{2}}{R_{2}}\right)
$$

where $R_{1,2}$ are the radii of the two bubbles $\dot{R}_{1}$ and $\dot{R}_{2}$ their growth rates, respectively. This expression shows that the pressure difference between two bubbles arises from capillary pressure $\left(1^{\text {st }}\right.$ term on RHS), and the viscous resistance to bubble growth $\left(2^{\text {nd }}\right.$ term on RHS). The viscous growth term requires that neighboring bubbles grow at different rates (a.k.a., growth-rate dispersion), in order to generate that differential pressure. 
Figure 8 shows the differential pressures arising from the viscous and capillary terms for a simplified case of a dimple-free bubble pair having an 50\% size offset and growing within an infinite viscous $\left(\mu=10^{6}-10^{8} \mathrm{~Pa}\right.$ s $)$ melt. Two of the curves show the evolution of differential viscous stress between bubbles whose growth rates differ by half a log-unit $(5.0 \mathrm{x}$ $10^{-8}$ to $\left.10^{-7} \mathrm{~m} \mathrm{sec}^{-1}\right)$; this growth rate difference falls within the range of possible growth rates in the experiments as determined by VSD analysis (Table 1). The third curve shows the differential capillary pressure for a bubble pair having a $\sim 50 \%$ size offset but growing at the same rates. In general, the predicted differential stresses are small $\left(\sim 10^{2}-10^{6} \mathrm{~Pa}\right)$. For a given melt viscosity, they are greatest when the bubbles are smaller than $100 \mu \mathrm{m}$ and then rapidly decay as the bubbles grow to several hundred microns in size. Bubbles that have grown to several hundred microns in size are thus less likely to form dimples, as the stresses produced are quite modest. This effective size limit shows that dimple formation will likely be restricted to the early stages of magma decompression, when bubbles are small and of low total volume fractions. We note that the differential pressure arising from viscous resistance noticeably outweighs the effects of bubble capillarity, in some cases by more than two orders of magnitude. The offset depends strongly on the melt viscosity and is less pronounced when the melt viscosity is reduced to values expected in hydrous rhyolite magma (curve with $10^{6} \mathrm{~Pa}$ sec in Fig. 8).

Although the non-linear growth of unimodal bubble populations has been modeled with success (e.g., Navon and Lyakhovsky, 1998), precise estimate of the growth rate of single bubbles is precluded by the heterogeneous sizes and spatial distribution of the experimental bubble populations (Figs. 3, 4). We instead look for an upper limit to growth dispersion for the experimental conditions prevailing in the study by Burgisser and Gardner (2005). Focusing on a small volume and assuming for now that bubbles all have the same size at a 
given moment and are distributed homogeneously in space, the bubble radius is given by (e.g., Lensky et al 2004):

$R=\left(\frac{3 \alpha}{4 \pi N_{T}(1-\alpha)}\right)^{1 / 3}$

where $N_{T}$ is bubble number density $\left(\mathrm{m}^{-3}\right)$. The derivative of Eq. 7 gives a theoretical growth rate:

$\dot{R}=\frac{R}{3 \alpha(1-\alpha)} \dot{\alpha}$

If decompression rates are slow enough to ensure equilibrium bubble growth the evolution of porosity, $\alpha$, follows (e.g., Jaupart and Allègre, 1991):

$\frac{1}{\alpha}=1+\frac{M P}{G T \rho \kappa\left(\sqrt{P_{i}}-\sqrt{P}\right)}$

where $M$ is the molecular weight of water, $G$ is the ideal gas constant, $T$ is temperature, $\rho$ is melt density, $\kappa$ is Henry's Law constant, and $P_{i}$ is the initial pressure that defines the total water content in the system. Following Burgisser and Gardner (2005), the equilibrium growth rate can be related to decompression rate, $\dot{P}(\mathrm{~Pa} / \mathrm{s})$, by deriving Eq. 9 with respect to time ${ }^{1}$, which cancels all constants except $P_{i}$. Replacing the result in Eq. 8 gives:

$\dot{R}=\frac{R \dot{P}}{3 P}\left[1+0.5\left(\sqrt{P_{i} / P}-1\right)^{-1}\right]$

When decompression rates are large $(>0.1 \mathrm{MPa} / \mathrm{s})$, two disequilibrium growth regimes can take place (Burgisser and Gardner, 2005). Focusing on the fastest of these regimes, the growth rate can be estimated by:

$$
\dot{R}_{f a s t}=\dot{R}+\frac{R\left(a_{2} \dot{P}+b_{2}\right)}{3 \alpha(1-\alpha)}
$$

\footnotetext{
${ }^{1}$ The derivative of Eq. 10 has been reported as Eq. (A9) in Burgisser and Gardner (2005) with a typo; the term $-\sqrt{P} / 2$ should be multiplied by $\beta\left(\sqrt{P_{0}}-\sqrt{P}\right)^{1}$.
} 
where $a_{2}=2.36 \times 10^{-4}$ and $b_{2}=6.46 \times 10^{-8}$ are empirical constants determined by Burgisser and Gardner (2005). An estimate of the dispersion of growth rates can be done by comparing the relevant theoretical rates ( $\dot{R}$ and $\dot{R}_{\text {fas }}$ ), which both assume monosized distribution, for the average, maximum and minimum bubble sizes reported in Table 1. Typical experimental growth dispersion, measured as the ratios between either maximum and average values, or average and minimum values, lies between 1.2 and 4.3. Theoretical growth dispersion spans a similar range because rates of the average bubble size from Eqs. (10-11) are 1.2 to 3.5 times larger (or smaller) than the average growth rates reported in Table 1. Overall, these estimates suggest that actual growth rates were not larger or smaller than 4 times the average rates reported in Table 1. We thus estimated the upper limit of $\Delta P$ by using Eq. (6) and assuming that the penetrator bubble was growing four times faster than the average rate while the dimpled bubble was growing four times slower than the average rate. Melt viscosity is calculated using the relationship by Hess and Dingwell (1996) with the water solubility law within Eq. (9) and $\kappa=3.44 \cdot 10^{-6} \mathrm{~Pa}^{-1 / 2}$ (Burgisser and Gardner, 2005).

The lower limit of $\Delta P$ cannot be estimated by the same method because Eqs (10)-(11) predict that bubbles grow at a rate proportional to their respective initial sizes. As a result, the viscous term of $\Delta P\left(2^{\text {nd }}\right.$ term on the RHS of Eq. 6) systematically vanishes and dimples are predicted to form only when the penetrator bubble is smaller than the other bubble, with $\Delta P$ controlled only by capillary pressure. Cases where the penetrator bubble is larger than the other bubble are, however, frequent (Fig. 5). We thus estimate the minimum bending pressure difference by calculating the capillary pressure necessary to maintain the un-dimpled IBF. We have seen the theoretical arguments behind the fact that bended IBFs tend to be shaped like paraboloids if they are thick, and like sections of spherical shells if surface tension forces dominate. The $3 \mathrm{D}$ reconstructions suggest that the surfaces of the IBFs might be shaped like paraboloids or spheroids, but not like spheres (Fig. 4). A spheroid has a radius of curvature at 
the apex twice that of an ellipsoid. We choose to calculate the minimum pressure drop, $\Delta P_{\min }$, assuming spheroid-shaped IBFs:

$$
\Delta P_{\min }=\frac{4 \sigma h}{a_{0}^{2}}
$$

where $a_{0}$ is the half-wavelength of the deformed IBF (which corresponds to the radius of the IBF when it is flat; Fig. 6c) and $h$ is the amplitude of the deformed IBF.

Three first-order timescales can thus be calculated from our data: the timescales for IBF viscous deformation, $t_{b e n d}$ and $t_{\text {stretch }}$, which depend on the maximum and minimum pressure differences between the bubbles, and the time for capillary pressure to reestablish spherical bubbles, $t_{\text {relax }}$. We calculated these deformation timescales for 20 experimental dimple-bearing bubble pairs and compared them to the experimental duration of the four runs that generated them (Fig. 9). Bending times are short, on the order of $10^{-4}-10^{-1} \mathrm{~s}$. They are followed by stretching times that range from $10^{-1}$ to $10^{2} \mathrm{~s}$. Relaxation times, which span from $10^{1}$ to $10^{2} \mathrm{~s}$, are systematically the longest timescales. Results displayed in Fig. 9 suggest that surface tension played a subordinate role in bending IBFs because bubble relaxation times sometimes exceed decompression times. Our observations of dimpled IBFs suggest they were formed when bubbles were in close proximity and thus had nearly their final sizes, shortly before quenching. This is consistent with deformation being done by viscous stretching of the IBFs seconds to minutes before quenching. It follows that the force driving IBF deformation is the pressure difference between two bubbles, which necessarily includes a contribution from growth rate dispersion in cases where the largest bubble is the penetrator.

\subsection{Dimple preservation}

At any given moment there may be a number of dimples forming in a volume of decompressing bubbly melt, some of which will rupture and then relax to become coalesced bubbles, others that will relax back to the spherical form of the larger bubble before 
quenching, and some of which get "caught in the act" of forming by the quench event. The dimple structures are prevalent in the experiments in part because the conditions for their preservation were met (e.g., rapid quenching). Dimples will be preserved only if both interacting bubbles do not relax back to a spherical shape under the influence of surface tension. An analogous natural scenario that would foster this relaxation could involve the cessation of decompression-driven bubble growth (and thus differential viscous stress between two bubbles), perhaps due to stalled magma ascent, followed by a period of cooling (dwell) above the glass transition temperature. In the experiments whose final quenching pressure is $\sim 40 \mathrm{MPa}$, bubbles could relax over a time scale of $10^{3}$ secs, much longer than the experiment quenching time (a few secs, Fig. 9). Relaxation timescales of the dimple structure itself are shorter, because of the small length scale of the dimple, (ie., $R$ in Eq. 3 now equals the dimple radius-of-curvature). In the case of a $10 \mu \mathrm{m}$-deep dimple, relaxation would occur in about $100 \mathrm{sec}$. Both time scales are much longer than experimental quenching times. Dimple preservation in the experiments was thus guaranteed.

In contrast to the experimental rhyolites, there are very few dimple structures in natural obsidian and pumice pyroclasts. This observation may reflect several factors related to unfavorable formation and/or preservation conditions, including: 1) relatively higher melt viscosities in the natural rhyolite stemming from their lower water contents, 2) protracted, slow quenching times $(>1000 \mathrm{sec})$ allowing complete dimple relaxation, as could be the case in lava or during a repose interval of ascending bubbly rhyolite, and 3) lower quench pressures leading to an overprinting, or erasure of dimple structures by another IBF-thinning mechanisms, such as stretching during bubble expansion.

We have already demonstrated that the driving force due to differential pressure and hence dimple formation declines rapidly with increasing bubble size (Fig. 8). This effect alone might explain the lack of dimples in the natural rhyolite pumices, whose bubble sizes 
are on average much higher than one hundred microns (Fig. 2) and therefore within the realm of reduced viscous and capillary stress (Fig. 8). Another effect hindering dimple formation in the natural case is that bubbles in natural pumice are crowded, which results in individual bubbles interacting with others in all directions. This means that the outward growth of a bubble is not buttressed by a significant volume of melt, but rather, by the low-viscosity vapour within neighboring bubbles. Under these conditions, viscous stresses will be greatly diminished.

Dimple formation may also be inhibited by heightened viscosity commensurate with extensively degassed silicic melt at shallow pressures. This would increase the relaxation timescale (and decrease deformation rate at a given fixed applied stress) and the amount of time and stress needed to buckle the wall. As we show in the following section, many of these factors will compete with one another such that a combined parametric description of bubble coalescence mechanisms is needed.

\section{Discussion and implications for natural eruption processes}

Our analysis highlights three important bubble-coalescence mechanisms in viscous silicate melts: drainage, planar stretching, and dimpling. The conditions under which these bubble coalescence mechanisms operate during the rise of silicic magma can be assessed by comparing estimated timescales for the three different IBF-thinning mechanisms $\left(t_{\text {drain }}, t_{\text {planar }}\right.$, and $t_{\text {stretch }}$, which, for clarity, will be named $t_{\text {dimple }}$ in this section), the bubble relaxation timescale $\left(t_{\text {relax }}\right.$; the time it takes for two newly dimpled bubbles of initial radii $R_{1}$ and $R_{2}$ to recover their spherical shapes after being dimpled, and the time a parcel of magma would take to decompress from a given pressure to atmospheric pressure $\left(t_{\text {decomp }}\right)$. The main parameters controlling these timescales are the initial pressure, melt viscosity, bubble sizes and growth rates. We calculated representative values for each of these parameters for the following 
types of eruption: 1) effusive lava dome, 2) Vulcanian eruption of a partly degassed magma column, 3) Plinian and 4) sub-Plinian explosive eruptions. The two first cases involve opensystem degassing, for which we imposed an upper limit to porosity at $40 \mathrm{vol} \%$. The last two cases are assumed to occur under closed-system degassing. For simplicity, we assumed that magma decompresses at a constant rate (for a range of eruption regimes) and quenches instantaneously once it reaches $\mathrm{P}=0.1 \mathrm{MPa}$.

The timescales are plotted as a function of pressure in Fig. 10. For instance, a bubble pair at $60 \mathrm{MPa}$ would be $50 \mu \mathrm{m}$ (calculated assuming equilibrium degassing from the storage pressure at $250 \mathrm{MPa}$, Eqs 7-8) and $75 \mu \mathrm{m}$ (assumed to be 1.5 times larger). If decompressed at $10 \mathrm{MPa} / \mathrm{s}$, the pair would take $t_{\text {decomp }} \sim 6 \mathrm{~s}$ before reaching atmospheric pressure (arrow in Fig. 9A). Both $t_{\text {dimple }}$ and $t_{\text {planar }}$ are of the same order of magnitude (1 to $10 \mathrm{~s}$ ), but $t_{\text {relax }}$ and $t_{\text {drain }}$ are much larger $\left(10^{3}\right.$ and $10^{6} \mathrm{~s}$, respectively). These relative orders of magnitudes suggest that a bubble pair at $60 \mathrm{MPa}$ could coalesce by dimple formation or planar wall stretching and that the shapes of the IBF are likely to be preserved, but that melt drainage is improbable.

The magma decompression paths shown in Fig. 10, superposed on various bubble coalescence regimes, highlight which processes are likely to take place during the ascent of silicic magmas. Note, firstly, that by virtue of $t_{\text {drain }}$ being much greater than the other timescales, melt-wall drainage will be prohibitively slow and will not likely govern bubble coalescence in any of the eruption regimes. Overall, coalescence by planar-wall stretching occurs over similar timescales as decompression durations, making it feasible in any of the four eruptive styles and consistent with natural observations (Fig. 1). Dimple formation is likely to occur in explosive regimes, but only during the initial stages of magma ascent extending from high pressure to $\sim 50 \mathrm{MPa}$. At these high pressures, the dimple formation timescale is shorter than that of planar wall stretching, although both mechanisms could 
occur. Below $20 \mathrm{MPa}$, however, the timescale of planar-wall stretching becomes shorter than that of dimpling - there is a crossover between 20 and $50 \mathrm{MPa}$, depending on eruptive regime - and thus stretching would act more efficiently at shallow pressures, which again is consistent with observations of natural pumiceous pyroclasts (Fig. 2).

Dimple relaxation requires more time than that afforded by the decompression paths in Plinian, sub-Plinian, and Vulcanian eruptions, thereby making it unlikely to erase the textures created by dimpling. Only in the lava dome regime do the timescales for dimple relaxation fall within the available decompression time. Whereas the preservation of planar IBFs is likely because of their broad pressure range of formation, dimple structures are more likely to be overprinted during decompression to lower pressures at which point bubble crowding (Fig. 2) and growth can cause a sharp decline in the driving forces for dimple formation (Fig. 8). In the case of effusive eruptions, both planar IBFs and dimples are likely to be erased by bubble relaxation to spherical shapes, IBF rupture and melt-film retraction, or quite possibly shearing and bubble collapse (e.g., Carrichi et al., 2011).

\section{Concluding remarks}

We have identified various bubble coalescence mechanisms in natural and experimental rhyolite samples and calculated the stresses, timescales, and P-T regimes over which these mechanisms operate. While bubbles in silicic magma may coalesce by any of the following three mechanisms, melt film drainage, stretching, and/or dimpling, the preferred coalescence mechanism depends strongly on time, the intensive and physical parameters of the melt-bubble suspension (e.g., pressure, temperature, viscosity), and on the relative growth rates and sizes of the bubbles involved. For the main reason that rhyolite magma is highly viscous, bubble coalescence via melt wall drainage will not likely occur in most eruptions of silicic magma. 
Bubble coalescence is instead expected to occur via inter-bubble melt film (IBF) stretching under a relatively broad range magma ascent conditions. We expect stretching to dominate as the magma becomes extensively degassed and very porous in the shallow reaches of the volcanic conduit. Perhaps slightly before IBF stretching kicks in, the formation of dimpled IBFs may facilitate coalescence during the early stages of magma decompression, when bubbles are small $(<200 \mu \mathrm{m})$ and of low total volume fractions. IBF dimpling requires modest differential bubble pressures to exist, and these may arise from either bubble size capillarity, or bubble growth rate dispersion.

Our analysis has shown that bubbles coalesce only after some work has been performed on the IBF, either from bubble growth, or from the deformation attendant with differential bubble pressures acting across the IBF. In either case - dimpling or stretching bubble coalescence is in inextricably linked to the growth history of the bubble population. Volcanic eruption models could improve if, for example, they account for the size distributions of bubbles along with interactions-based laws describing their evolution during growth and coalescence.

\section{Acknowledgements}

The authors thank J. E. Gardner for experimental samples and discussions. J.M.C. thanks the ISTO and the ERC grant 202844 under the European FP7 for supporting this project. Benoit Cordonnier provided useful comments on an earlier draft. 
Blower, J.D., Keating, J.P., Mader, H.M., and Phillips, J.C. (2001a) Inferring volcanic degassing processes from vesicle size distributions. Geophys. Res. Lett., 28: 347-350.

Blower, J.D., Mader, H.M., and Wilson, S.D.R. (2001b) Coupling of viscous and diffusive controls on bubble growth during explosive volcanic eruptions. Earth Planet. Sci. Lett. 193: 47-56.

Burgisser, A. and Gardner, J.E. (2005) Experimental constraints on degassing and permeability in volcanic conduit flow. Bull. Volcanol., 67: 42-56.

Caricchi, L., Pommier, A., Pistone, M., Castro, J., Burgisser, A. and Perugini, D. (2011) Strain-induced magma degassing: insights from simple-shear experiments on bubble bearing melts. Bull. Volcanol. 73: 1245-1257.

Castro, J.M. and Dingwell, D.B. (2009) Rapid ascent of rhyolite magma at Chaitén volcano, Chile. Nature. 461: 780-783.

Eichelberger, J.C., Carrigan, C.R., Westrich, H.R. and Price, R.H. (1986) Non-explosive silicic volcanism. Nature, 323: 598-602.

Eichelberger, J.C. (1995) Silicic volcanism: ascent of silicic magmas from crustal reservoirs. Ann. Rev. Earth. Planet. Sci., 23: 41-63. 
Gardner, J.E., and Ketcham, R.A. (2011) Bubble nucleation in rhyolite and dacite melts: temperature dependence of surface tension. Contrib. Mineral. Petrol. 162: 929-943.

Gonnermann, H. and Manga, M. (2007) The fluid mechanics inside a volcano. Ann. Rev. Fluid. Mech., 39: 321-356.

Hess, K-U., and Dingwell, D.B. (1996) Viscosities of hydrous leucogranitic melts: A nonArrhenian model. Am. Mineral., 81: 1297-1300.

Howell, P.D. (1996) Models for thin viscous sheets. European J. Appl. Math. 7: 321-343.

Ida, M.P., and Miksis, M.J. (1995) Dynamics of a lamella in a capillary tube. SIAM J. Appl. Math. 55: 23-57.

Jaupart, C. and Allegre, C. (1991) Gas content, eruption rate and instabilities of eruption in silicic volcanoes. Earth Plan. Sci. Lett., 102: 413-429.

Ketcham, R.A. (2005) Computational methods for quantitative analysis of three-dimensional features in geological specimens. Geosphere., 1: 32-41.

Klug, C. and Cashman, K.V. (1996) Permeability development in vesiculating magmas: implications for fragmentation. Bull. Volcanol., 58: 87-100. 
Kozono, T., and T. Koyaguchi (2009) Effects of relative motion between gas and liquid on 1dimensional steady flow in silicic volcanic conduits: 2 . origin of diversity of eruption styles. J. Volcanol. Geotherm. Res. 180: 37-49.

Lensky, N.B., Navon, O., and Lyakhovsky, V. (2004) Bubble growth during decompression of magma: experimental and theoretical investigation. J. Volcanol. Geotherm. Res., 129: 722.

Mangan, M., and Sisson, T. (2005) Evolution of melt-vapor surface tension in silicic volcanic systems: Experiments with hydrous melts. J. Geophys. Res. 110, B01202.

Melnik, O., and R. Sparks (1999), Nonlinear dynamics of lava dome extrusion. Nature, 402: $37-41$.

Navon, O. and Lyakhovsky, V. (1998) Vesiculation processes in silicic magmas. In: Gilbert J. S. and Sparks, R.S.J. (eds.) The physics of explosive eruptions. Geological Society of London, Special Publications. 145: 27-50.

Okumura, S., Nakamura, M., and Tsuchiyama, A. (2006) Shear-induced bubble coalescence in rhyolitic melts with low vesicularity. Geophys. Res. Lett., 33 L20316, doi: 10.1029/2006GL027347.

Proussevitch, A.A., Sahagian, D.L., Anderson, A.T. (1993) Stability of foams in silicate melts. J. Volcanol. Geotherm. Res., 59: 161-178. 
Ribe, N.M. (2001) Bending and stretching of thin viscous sheets. J. Fluid Mech. 433: 135160.

Rust, A.C., Cashman, K.V., and Wallace, P.J. (2003) Determining flow type, shear rate and shear stress in magmas from bubble shapes and orientations, J. Volcanol. Geotherm. Res., 122: $111-132$.

Slezin, Y. B. (2003) The mechanism of volcanic eruptions (a steady state approach), $J$. Volcanol. Geotherm. Res., 122 (1-2): 7-50.

Toramaru, A. (1988) Formation of propagation pattern in two-phase flow systems with application to volcanic eruptions. Geophysical Journal, 95: 613-623.

Tuck, E.O., Stokes, Y.M., and Schwartz, L.W. (1997) Slow slumping of a very viscous liquid bridge. J. Engineering Math. 32: 27-40.

Tuffen, H. and Castro, J.M. (2009) The emplacement of an obsidian dyke through thin ice: Hfafntinnuhryggur, Krafla Iceland. J. Volcanol. Geotherm. Res., 185: 352-366.

Walker, D. and Mullins, Jr., O. (1981) Surface tension of natural silicate melts from 1,2001,500 ${ }^{\circ} \mathrm{C}$ and implications for melt structure. Contrib. Min. Pet., 76: 455-462.

Westrich, H.R. and Eichelberger, J.C. (1994) Gas transport and bubble collapse in rhyolitic magma: an experimental approach. Bull. Volcanol. 56: 447-458. 
Woods, A. W., and T. Koyaguchi (1994), Transitions between explosive and effusive eruptions of silicic magmas. Nature, 370 (6491): 641-644.

Vaynblat, D., Lister, J.R., and Witelski, T.P. (2001) Rupture of thin viscous films by van der Waals forces: Evolution and self-similarity. Phys. Fluid., 13: 1130-1140.

Yoshida, S., and T. Koyaguchi (1999) A new regime of volcanic eruption due to the relative motion between liquid and gas. J. Volcanol. Geotherm. Res., 89 (1-4): 303-315. 


\section{Figure Captions:}

Figure 1. X-Ray $\mu$-CT renderings of vesicle structures in low-porosity volcanic glass highlighting dominant inter-bubble melt structures (IBFs) in bulk populations (upper) and on the scale of 2-3 individual bubbles (subjacent frames). Lower frames comprise 3D models and corresponding 2D slices (inset greyscale images) through the tomographic data. a, e) Chaitén rhyolite obsidian lapillus showing two bubbles sharing a flattened IBF. b, f) Krafla low-porosity obsidian with flat IBFs. c, g) Chaitén obsidian with sparse bubbles sharing predominantly bi-concave IBFs, h) low-porosity Chaitén pumice having interpenetrating bubbles and a dimple structure.

Figure 2. Two examples of Chaitén pumice lapilli showing $(a, b)$ the $3 \mathrm{D}$ rendering of tomographic data and (c, d) 2D slices through the data. Bubbles are large and deformed compared to obsidian sample and IBFs are almost exclusively the flattened variety. Note that smaller bubbles within the IBF were deformed by stretching during bubble crowding.

Figure 3. X-ray $\mu$-CT renderings of experimentally decompressed bubble-bearing rhyolite. Frames a-c show, respectively, the nucleation population (ABG1), bubbles grown at $1 \mathrm{MPa}$ $\mathrm{sec}^{-1}$ and quenched at $40 \mathrm{MPa}(\mathrm{ABG} 31)$, and bubbles grown at $0.025 \mathrm{MPa} \mathrm{sec}^{-1}$ and quenched at $44 \mathrm{MPa}$ (PPE2). In frames d-f, characteristic inter-bubble melt films (IBF) are provided, showing that the predominant IBF form varies as a function of decompression rate and experiment duration.

Figure 4. Vesicle size distributions (VSD) measured on rhyolite decompression experiments. All histograms show the true bubble diameter versus frequency with total number of 
observations given in parentheses. The nucleation population data (light grey bars) is overlain on subsequent plots corresponding to various decompression treatments. The offset between the nucleation population and decompression runs provides a measure of the amount of growth, either average, modal, or maximum, and combined with the experimental decompression time, gives an estimate of bubble growth rate. These data are used in models describing bubble dimpling dynamics and IBF stretching.

Figure 5. Relations between dimple geometry and bubble size difference. Horizontal axis is the ratio of the arc wavelength measured through the centerline of the dimple in cross section (figure right inset) and the dimple film thicknesss measured at the apex of the dimple. Data above the horizontal "zero line" are bubble pairs with a bigger bubble penetrating a smaller one, whereas the opposite case holds below the line. Data are from experiments decompressed at $0.025 \mathrm{MPa} \mathrm{sec}{ }^{-1}$. Filled circles are the experiment quenched at $44 \mathrm{MPa}$, while triangles represent $\mathrm{P}_{\text {final }}$ of $40 \mathrm{MPa}$, and squares a $\mathrm{P}_{\text {final }}$ of $34 \mathrm{MPa}$.

Figure 6. Geometric simplification of the IBF used in the physical models. Labels on different geometric elements are defined in Table 2 and the text. a) Absence of draining for the IBF means that no melt flows out of the light gray cylinder defined by the edges of the IBF. b) Cross section of a planar IBF (gray) forming a cylinder. An advanced stage of deformation by stretching is shown in dashed lines. c) Cross section of a dimpled IBF (gray). The initial stage of deformation is shown in dashed lines.

Figure 7. Bubble growth-coupled IBF thinning and stretching expressed as a) a model curve showing exponential decrease in IBF (wall) thickness as a function of bubble size for the case of a 2D constant mass, rectangular-shaped IBF thinning between two semi-circular bubbles. 
The small schematics at either end of the curve depict the qualitative change in the IBF (solid rectangle) between two bubbles (dashed). Inset images show a natural bubble pair with a flattened IBF of $\sim 5 \mu \mathrm{m}$ width. b). IBF thickness versus bubble growth timescale determined using the model shown in a) and a range of growth rates inferred from experiments (VSD analysis; Appendix 1).

Figure 8. Graph showing the differential pressure arising from two neighboring bubbles having different sizes and growth rates. These differences give rise to two types of differential bubble pressure, one stemming from surface tension, or capillarity (arising from a $50 \%$ size difference; curve labeled "capillary" with fine dashes), and the other due to viscous pressure arising from variable growth rates (bold dash and dash-dotted curves). The upper abscissa shows the relative bubble size whereas the lower scale indicates the penetrator bubble radius. Two viscous stress curves illustrate the cases for different melt viscosities. Bubble growth rates differ by $0.5 \log$ unit and range from $5 \times 10^{-8}$ to $10^{-7} \mu \mathrm{m} / \mathrm{sec}$. Both effects generate differential pressure across the IBF, however, these differential pressure drops precipitously as bubbles grow larger than about $100 \mu \mathrm{m}$ in radius.

Figure 9. Dimple dynamics calculations in decompression experiments (see Fig. 6c for the geometrical setup of a dimple structure). Grey boxes represent timescales for IBF bending into dimples Dimple formation (solid symbols) and breakup (open symbols) points pressures are shown for 20 bubble pairs from 4 decompression experiments. The dashed lines indicate quench pressures (40 MPa for all pairs except 3 that were quenched at $44 \mathrm{MPa}$ ). Formation and breakup pressure were calculated using the decompression rate and the time given by solving numerically Eq. $(3,5-6)$ backward and forward in time, respectively. $\dot{R}_{1}$ is given by Eq. (10) at the quench pressure, $\dot{R}_{2}$ is given by Eq. (10) when $A \geq 1$ and is fixed at an arbitrary 
value that obeys Eq. (4) when $A<1, P_{i}=150 \mathrm{MPa}, \sigma=0.1 \mathrm{~N} / \mathrm{m}$ (Walker and Mullins, 1981), and $\alpha$ and $N_{T}$ are that measured by Burgisser $\&$ Gardner (2005). When $A<1$, the output is not sensitive to the exact value of $B$ as long as it is within the order of magnitude of the maximum value given by Eq. (4). $\left(t_{\text {bend }}\right)$, white boxes represent timescales for IBF stretching into dimples $\left(t_{\text {stretch }}\right)$, and triangles represent timescales for dimple to disappear because bubbles relax into spheres $\left(t_{\text {relax }}\right)$. Note that boxes are slightly shifted along the y-axis for clarity. The 1:1 line marks experimental duration, which represents the maximum time available for dimpling to occur.

Figure 10. Pressure-time regimes under which the three different bubble coalescence mechanisms operate, including reference curves showing the pressure-time paths of viscous magmas undergoing: A) fast decompression under closed-system degassing (curves labeled "Plinian" and "sub-Plinian"), and B) slow decompression under open-system degassing ("Vulcanian" and "dome" curves). Coalescence by dimple formation ( $t_{\text {dimple }}$, red), coalescence by melt drainage ( $t_{\text {drain }}$, gray), and the relaxation of a newly dimpled bubble pair their respective spherical shapes ( $t_{\text {relax }}$, green) are sensitive to melt viscosity, which was varied between that of a $825^{\circ} \mathrm{C}$ rhyolite (dotted lines) and that of a $950{ }^{\circ} \mathrm{C}$ rhyolite (solid lines). Coalescence by IBF planar stretching $\left(t_{\text {planar }}\right.$, blue $)$ and the time taken to reach atmospheric pressure from a given pressure $\left(t_{\text {decomp }}\right.$, thick black lines) are sensitive to decompression rate (continuous black and blue lines: fast decompression rate, dashed black and blue lines: slow decompression rate). The arrow illustrates the values of these timescales for a bubble pair at $60 \mathrm{MPa}$ decompressing at $10 \mathrm{MPa} / \mathrm{s}$. All curves were calculated based on a magma porosity given by Eq. (7), a growth rate $\dot{R}_{1}$ given by Eq. (9), and the following parameters: $N_{T}=10^{12} \mathrm{~m}^{-3}, R_{2} / R_{1}=1.5, \dot{R}_{2} / \dot{R}_{1}=1.5, a_{0}=R_{1} / 2 \mathrm{~m}, z_{0}=R_{1} / 10 \mathrm{~m}, z_{f}=0.5 \mu \mathrm{m}$, 
$\sigma=0.1 \mathrm{~N} / \mathrm{m}$, and $P_{i}=250 \mathrm{MPa}$. Melt viscosity was calculated using the Hess and Dingwell (1996) relationship with $\kappa=3.44 \cdot 10^{-6} \mathrm{~Pa}^{-1 / 2}$. 


\section{Appendix}

\section{Tomography Methods}

We implemented a number of image processing steps in order to reduce the noise inherent in the $\mu$-CT scans. We performed most of the noise reduction with ImageJ anisotropic diffusion filter and then converted the denoised grey-scale images to binary format. We characterized the geometry of the IBFs both qualitatively, by examining the general form of the interfaces throughout given tomographic volumes, and by measuring the wavelengths, amplitudes, and thicknesses of the glass wall at the point of maximum deflection between the bubbles. These three dimensional characteristics were measured on the binary image stacks with Blob3D software, which allows the user to manually select the individual bubbles for geometric characterization. We measured the volume of the dimpled walls using Blob3D, again with the plane tool, which separates the deformed region from the rest of the spherical bubble. These volumes measurements slightly overestimate the true volume of the dimple, as the planar section will truncate part of the curve defining the surface of the spherical bubble. The error associated with this separation routine is minor, however, and we estimate that to be less than $0.1 \%$ of the dimple volume and likely $0.01 \%$ of the total bubble volume.

\section{Determination of maximum and average bubble growth rates from VSDs}

The decompression experiments of Burgisser and Gardner (2005) were performed on pre-hydrated and pre-vesiculated rhyolite glasses. In order to create materials suitable for decompression experiments, they applied a pre-treatment involving rapid decompression of the hydrous rhyolite $\left(825^{\circ} \mathrm{C}\right.$ and equilibrated at $\left.160 \mathrm{MPa}\right)$ to a pressure of $100 \mathrm{MPa}$. This rapid decompression step generated a population of small bubbles that would grow in subsequent experiments according to the applied decompression regimen. We characterized 
the initial size distribution of this "dwell" population of bubbles with 3D X-Ray $\mu$ Tomography, the results of which are presented in Fig. 3. Changes to the bubble population during the different decompression histories were determined by comparing the VSDs in decompression experiments at different rates. Specifically, we measured the difference in the modal and maximum bubble size between the dwell population of the respective decompression runs (Fig. 4). This difference, divided by the experiment duration, yielded the average and maximum bubble growth rates. The resulting rates were used to estimate the magnitude of viscous stress that might arise if two neighboring bubbles grow at different rates. 

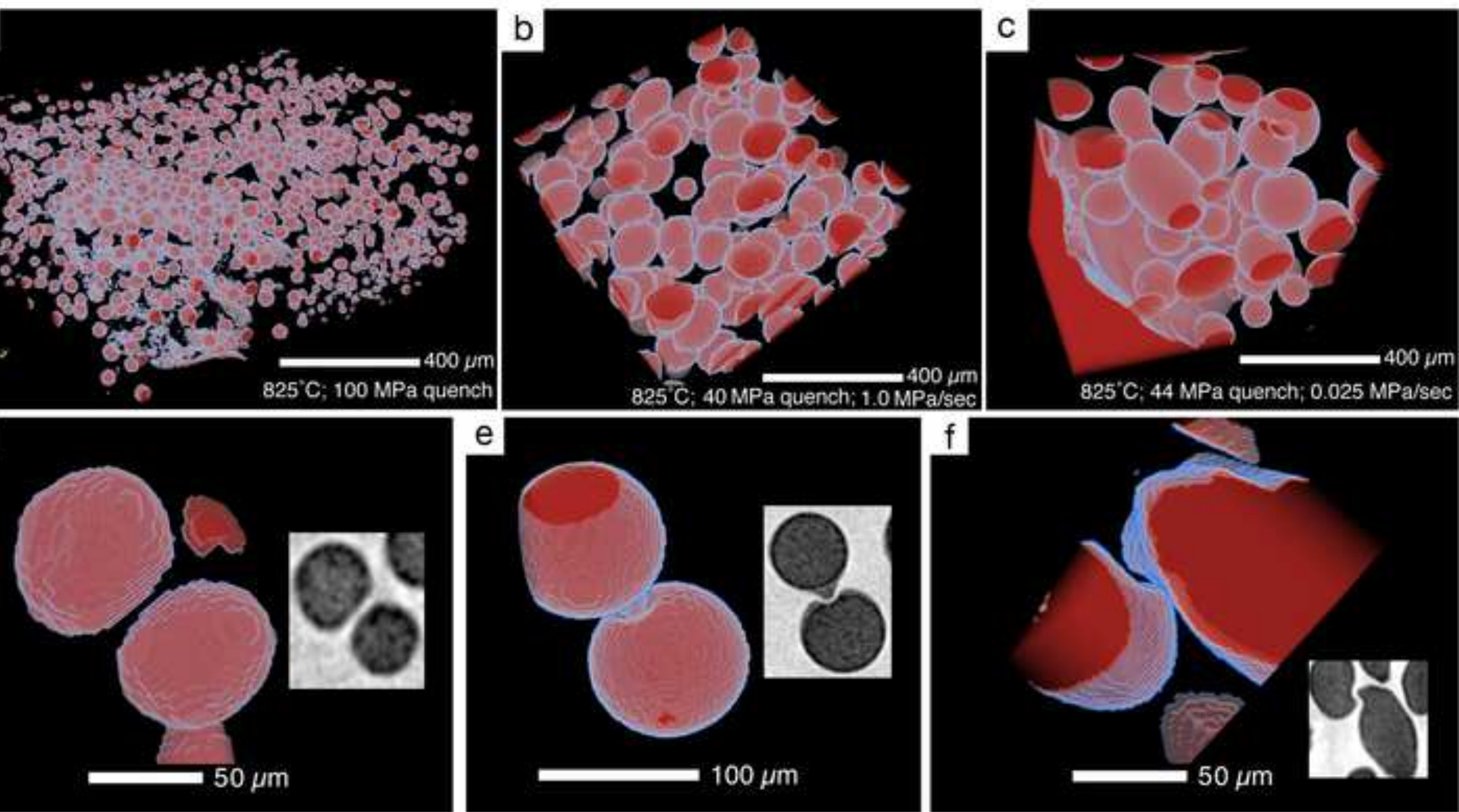

g.3., Castro et al 

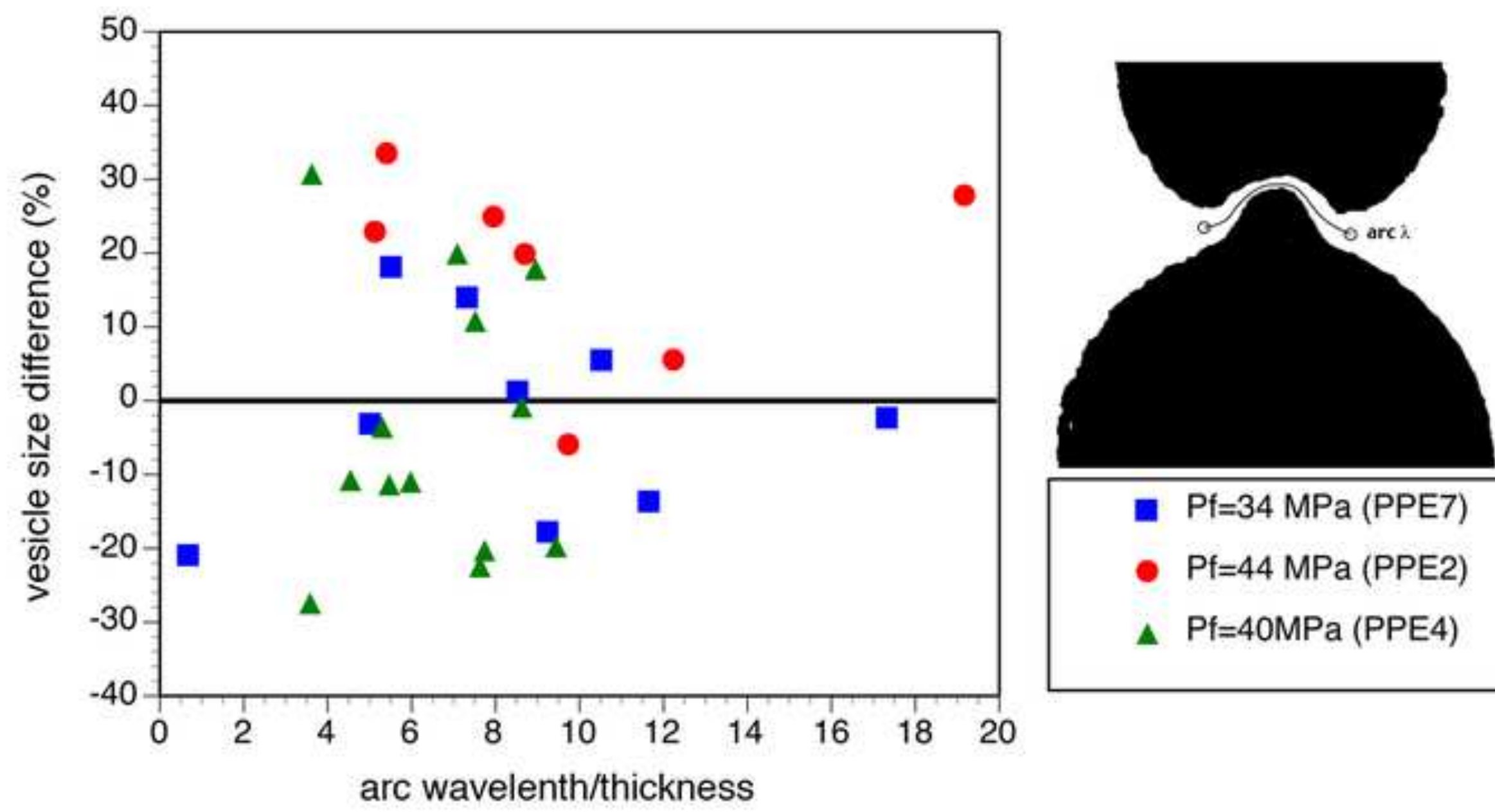

- $\mathrm{Pf}=34 \mathrm{MPa}$ (PPE7)

- $\mathrm{Pf}=44 \mathrm{MPa}$ (PPE2)

4. $\mathrm{Pf}=40 \mathrm{MPa}(\mathrm{PPE} 4)$

Fig. 5 ., Castro et al. 
A.
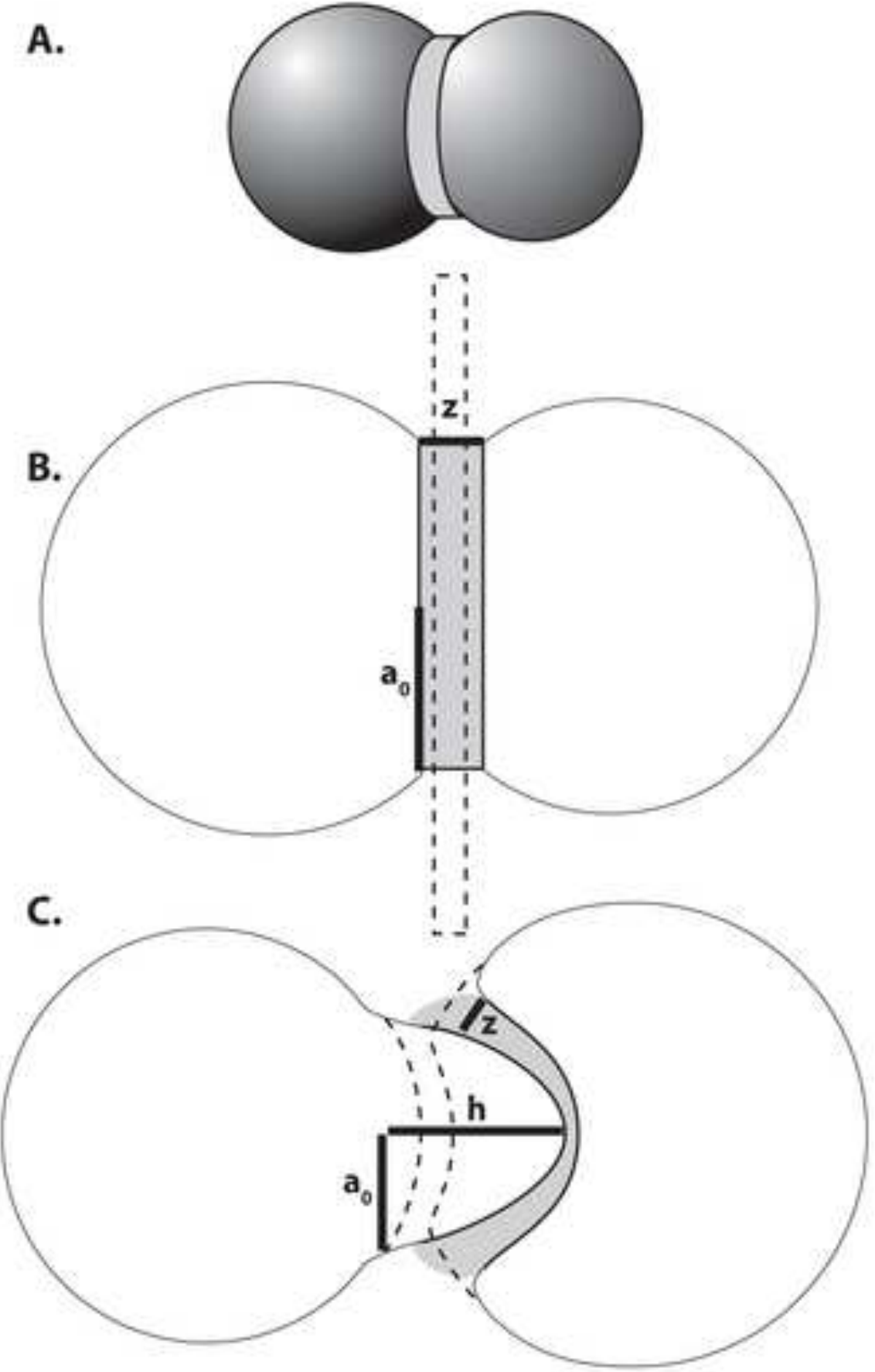

Castro et al., FIGURE 6 

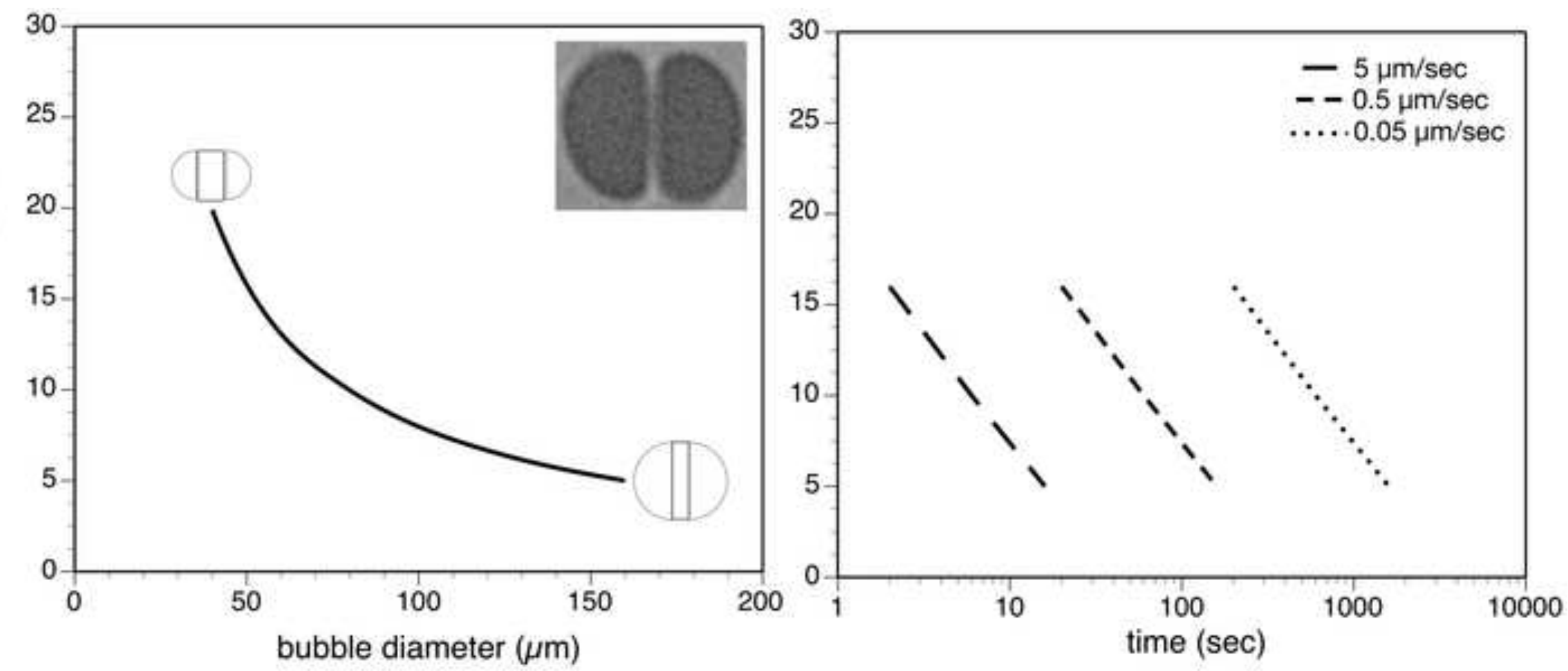

Fig. 7., Castro et al. 


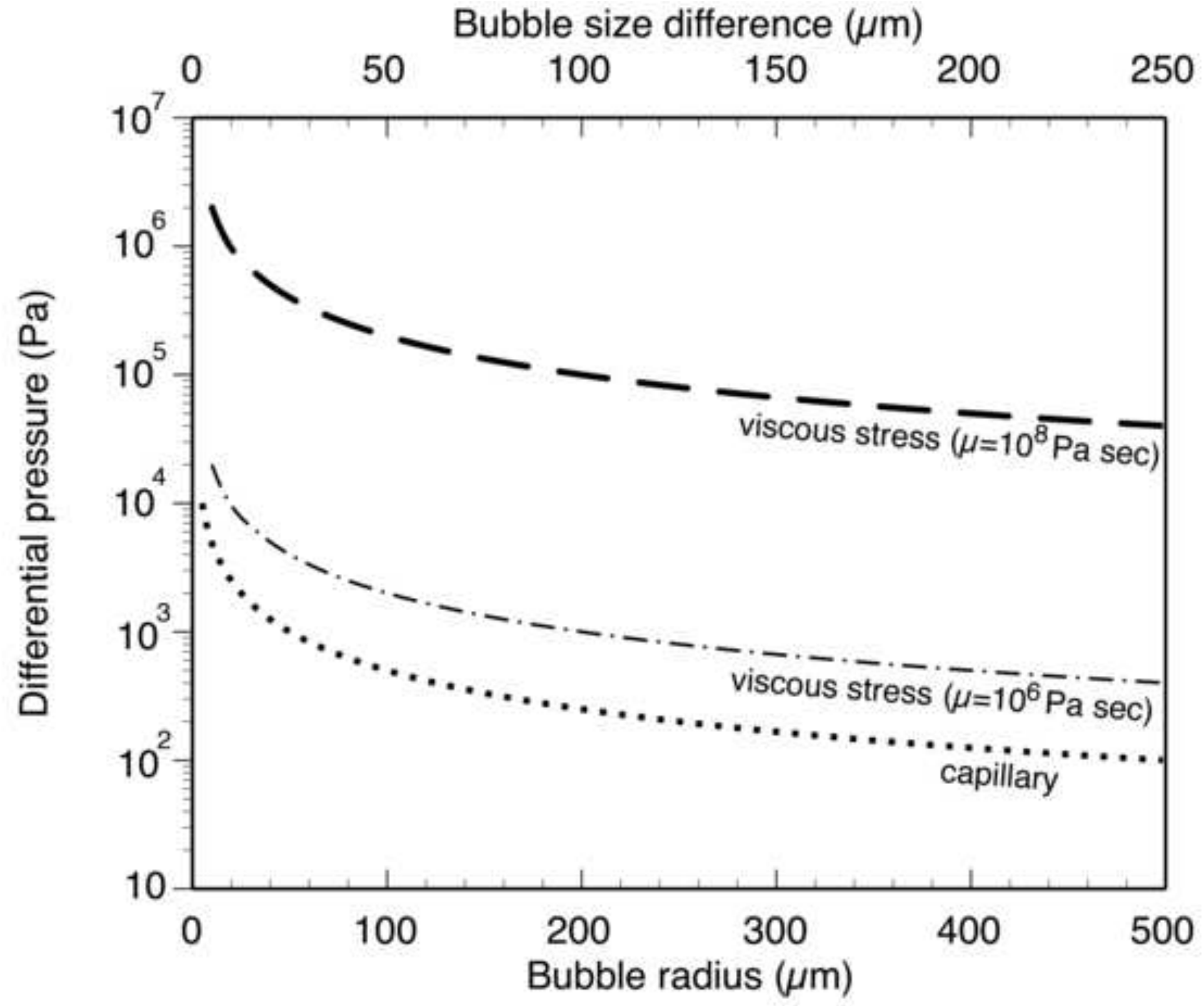

Fig.8., Castro et al. 


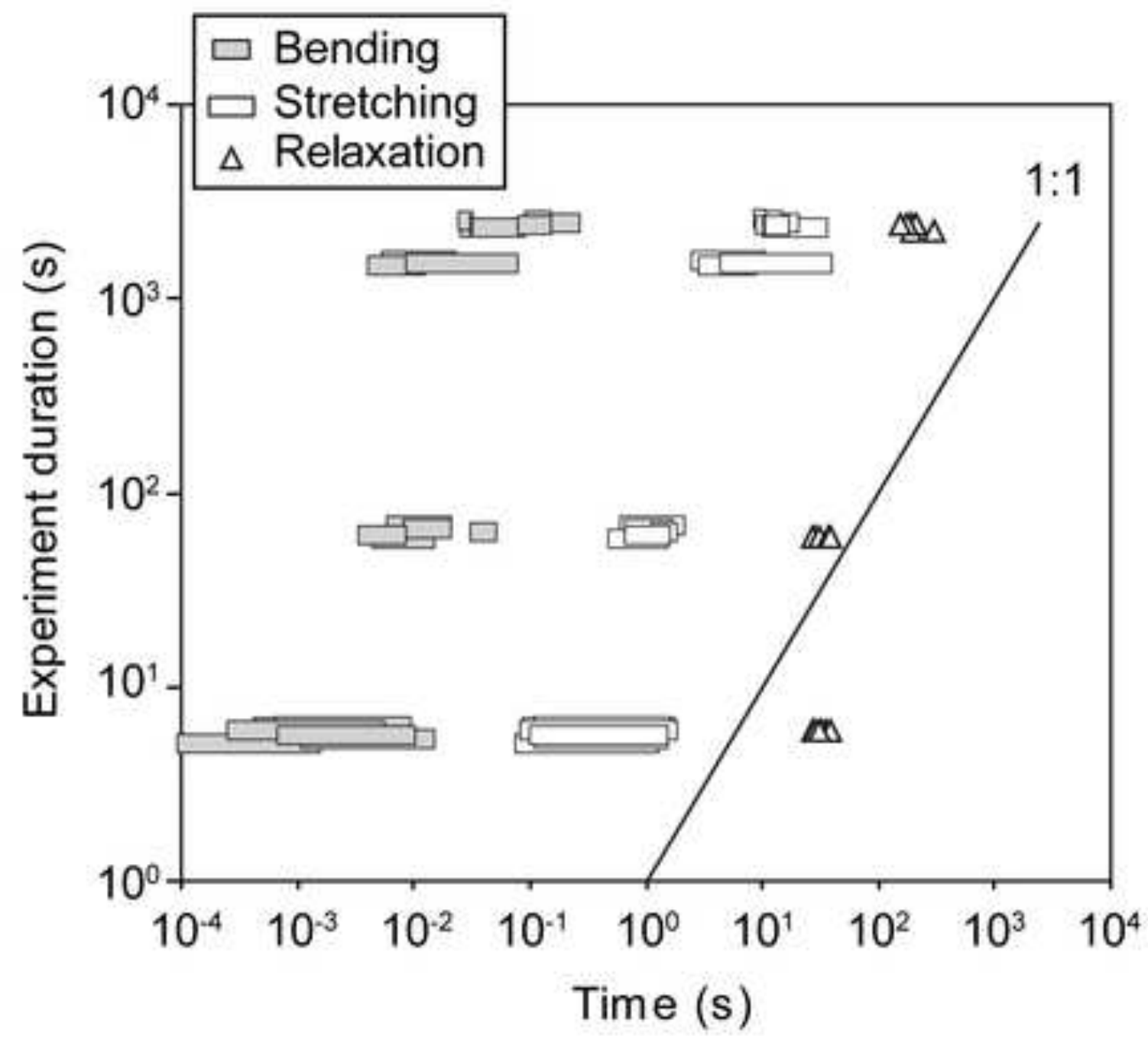

FIGURE 9, Castro et al. 
A) Closed system degassing

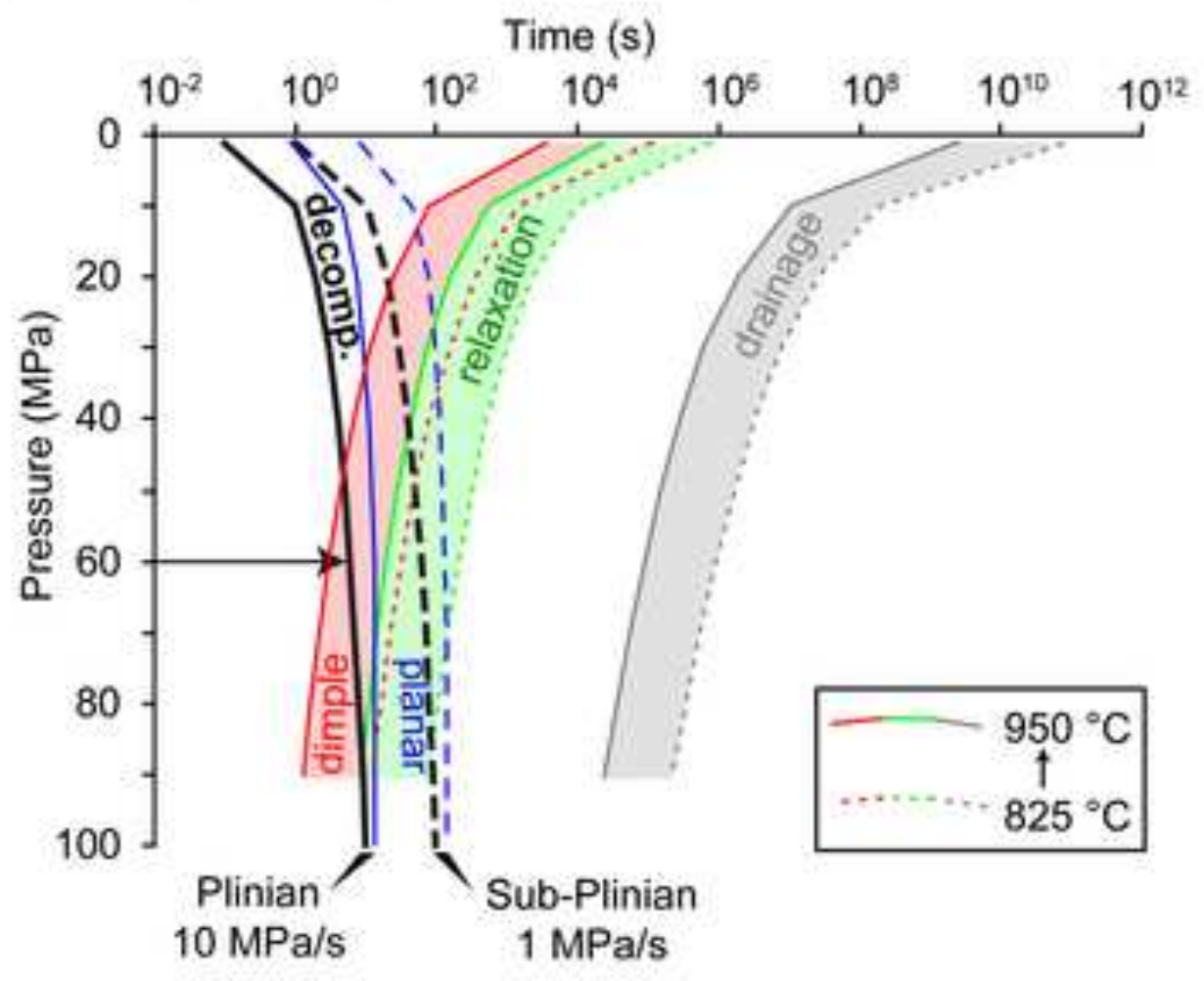

B) Open system degassing

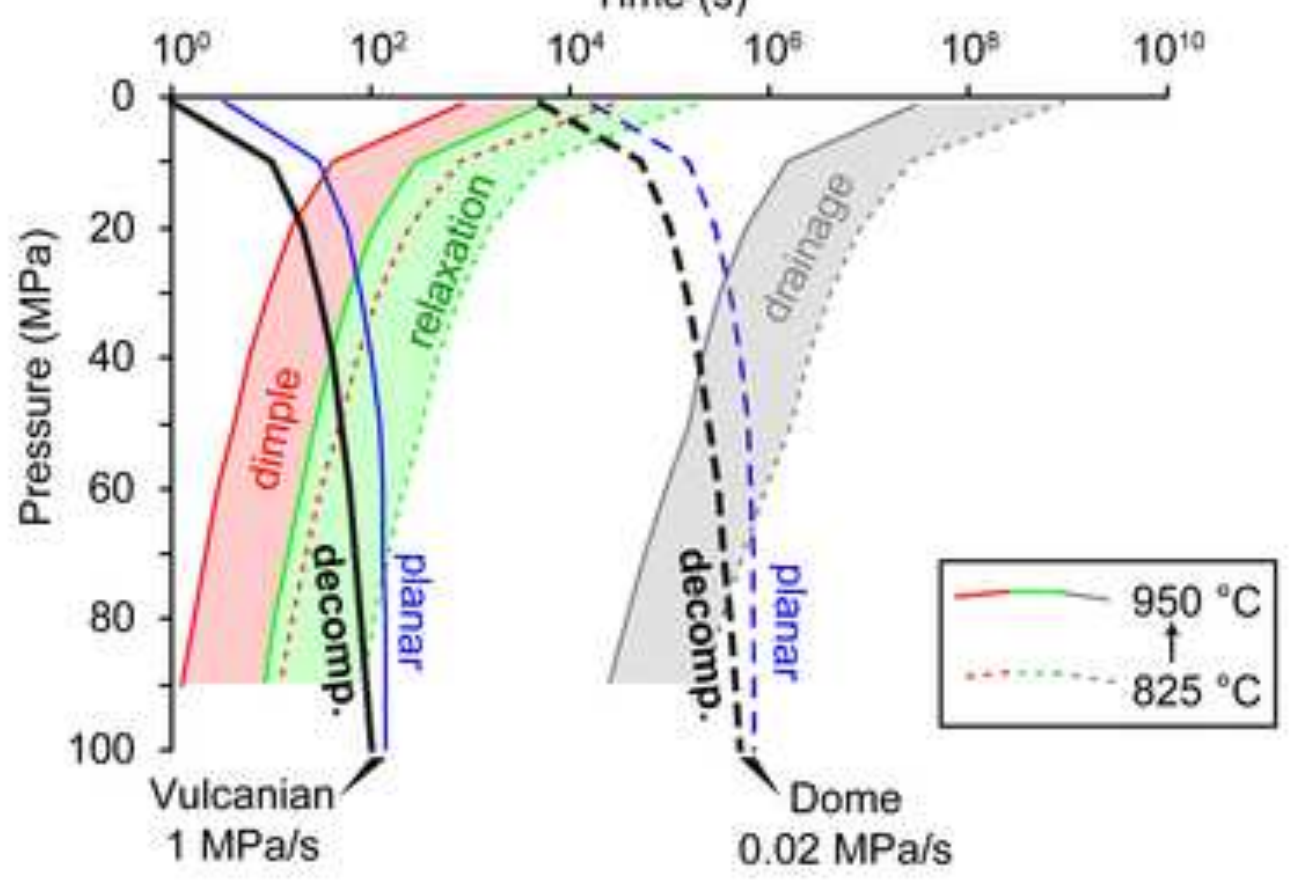

FIGURE 10, Castro et al. 
Table 1: Characteristics of bubbles in natural and experimentally produced bubbly melts. N.A. means not analyzed.

\begin{tabular}{|c|c|c|c|c|c|c|c|c|}
\hline \multicolumn{9}{|c|}{ Natural Pyroclasts } \\
\hline sample & $\begin{array}{c}\mathrm{H}_{2} \mathrm{O} \\
(\text { wt. \% })^{\varsigma}\end{array}$ & $\begin{array}{l}\text { Viscosity } \\
(\mathrm{Pa} \mathrm{s})^{£}\end{array}$ & $\begin{array}{c}\text { Crystallinity } \\
(\text { vol. \%) }\end{array}$ & $\begin{array}{c}\text { Porosity } \\
(\%)\end{array}$ & Bubble shape & IBF types ${ }^{\ddagger}$ & & \\
\hline Chaiten & $\sim 0.7-1.4$ & $4.1 \times 10^{6}-3.8 \times 10^{7}$ & 2 & $20-30$ & oblate & flat, bi-concave & & \\
\hline Krafla & 0.6 & $6.2 \times 10^{7}$ & $<1$ & 20 & spherical, oblate & flat, bi-concave & & \\
\hline \multicolumn{9}{|c|}{ Experimental rhyolite } \\
\hline Experiment $^{\S}$ & $\begin{array}{c}\mathrm{dP} / \mathrm{dT} \\
\left(\mathrm{MPa} \mathrm{s}^{-1}\right)\end{array}$ & $\begin{array}{l}\text { Quench pressure } \\
(\mathrm{MPa})\end{array}$ & $\begin{array}{l}\text { Decompression } \\
\text { Time (s) }\end{array}$ & $\begin{array}{l}\text { Porosity } \\
(\%)\end{array}$ & $\begin{array}{l}\text { Mean Diameter } \\
(\mu \mathrm{m})^{\dagger}\end{array}$ & $\begin{array}{l}\text { Growth Rate } \\
\left(\mathrm{m} \mathrm{sec}^{-1}\right)\end{array}$ & Bubble shape & IBF types ${ }^{\ddagger}$ \\
\hline $\mathrm{ABG} 1$ & N.A. & 100 & 900 & 5.6 & $28(19.2)$ & N.A. & spherical & flat, curved \\
\hline PPE2 & 0.025 & 44 & 2240 & 46.1 & $67(50.8)$ & $7 \times 10^{-8}$ & spherical & dimpled, curved \\
\hline PPE4 & 0.025 & 40 & 2400 & 51.2 & $69(19.8)$ & $5 \times 10^{-8}$ & spherical & dimpled, curved \\
\hline PPE7 & 0.025 & 34 & 2640 & 63.2 & $143(33)$ & $5.4 \times 10^{-8}$ & spherical & dimpled, curved \\
\hline ABG8 & 0.130 & 40 & 462 & 33 & $54.3(11.7)$ & $1.8 \times 10^{-7}$ & spherical & flat, curved \\
\hline ABG31 & 1.0 & 40 & 60 & 29.3 & $60.1(13.6)$ & $1.3 \times 10^{-6}$ & spherical & flat, curved, dimple \\
\hline ABG33 & 10.0 & 40 & 6 & 22 & $44.6(7.0)$ & $6.6 \times 10^{-6}$ & spherical & flat, curved, dimple \\
\hline
\end{tabular}

${ }^{\mathrm{s}}$ determined by SFTIR

E calculated assuming $825^{\circ} \mathrm{C}$ and using the relation of Hess and Dingwell (1996)

§all experiments except $A B G 1$ underwent isothermal decompression from $100 \mathrm{MPa}$ to the indicated final quench pressure

${ }^{\dagger}$ determined from 3D reconstructions except PPE7 that was measured in 2D; value in parentheses are 2 s.d.

${ }^{\ddagger}$ IBFs are listed in order of decreasing abundance 
Table 2: Summary of symbols.

\section{Quantities and units}

\section{Main variables:}

$a(t)=$ inter-bubble melt film (IBF) radius $(\mathrm{m}), a_{0}$ is initial radius

$h=$ dome-shaped IBF height $(\mathrm{m})$

$N_{T}=$ bubble number density $\left(1 / \mathrm{m}^{3}\right)$

$P=$ pressure $(\mathrm{Pa}), P_{i}$ is initial pressure

$\Delta P=$ inter-bubble pressure $(\mathrm{Pa}), \Delta P_{\min }$ is minimum bound

$R=$ bubble radius (m), $R_{1}$ and $R_{2}$ are the respective radii of a bubble pair

$\dot{R}=$ bubble growth rate $(\mathrm{m} / \mathrm{s}), \dot{R}_{\text {fast }}$ is maximum bound

$z(t)=\operatorname{IBF}$ thickness $(\mathrm{m}), z_{0}$ is initial thickness, $z_{f}$ is final thickness

$\kappa=$ Henry's constant $\left(\mathrm{Pa}^{-1 / 2}\right)$

$\alpha=$ porosity

$\mu=$ melt viscosity (Pa s)

$\sigma=$ surface tension $(\mathrm{N} / \mathrm{m})$

\section{Timescales:}

$t_{\text {drain }}=$ time for coalescence by IBF drainage (s)

$t_{\text {planar }}=$ time for coalescence by IBF planar stretching (s)

$t_{\text {bend }}=$ time for IBF bending $(\mathrm{s})$

$t_{\text {stretch }}=t_{\text {dimple }}=$ time for coalescence by IBF deformation/dimpling (s)

$t_{\text {decomp }}=$ time for a magma parcel to reach atmospheric pressure (s)

$t_{\text {relax }}=$ time for bubble shape to relax back to a sphere (s) 